\title{
Degree of dyspnoea at admission and discharge in patients with heart failure and respiratory diseases
}

Lourdes Vicent ${ }^{1}$, Juan Manuel Nuñez Olarte ${ }^{2,3}$, Luis Puente-Maestu ${ }^{3,4}$, Alicia Oliva ${ }^{4}$, Juan Carlos López ${ }^{1}$ Andrea Postigo ${ }^{1}$, Irene Martín ${ }^{1}$, Raquel Luna ${ }^{1}$, Francisco Fernández-Avilés ${ }^{1,3}$ and Manuel Martínez-Sellés ${ }^{1,3,5^{*}}$

\begin{abstract}
Background: Dyspnoea is a disabling symptom in patients admitted with heart failure (HF) and respiratory diseases (RD). The main aim of this study is to evaluate its intensity at admission and discharge and the relation with quality of life. We also describe its management, intensity, and evolution in HF and RD.

Methods: In this descriptive, cross-sectional study, we included prospectively all patients admitted with decompensated HF and chronic obstructive pulmonary disease (COPD)/pulmonary fibrosis during 4 months. Surveys quantifying dyspnoea (Numerical Rating Scale 1-10) and quality of life (EuroQoL $5 \mathrm{~d}$ ) were administered at discharge.

Results: A total of 258 patients were included: 190 (73.6\%) with HF and 68 (26.4\%) with RD (62 COPD and 6 pulmonary fibrosis). Mean age was $74.0 \pm 1.2$ years, and 157 (60.6\%) were men. Dyspnoea before admission was 7.5 \pm 0.1 . Patients with RD showed greater dyspnoea than those with HF both before admission $(8.1 \pm 0.2 \mathrm{vs} .7 .3 \pm 0.2$, $p=0.01)$ and at discharge $(3.2 \pm 0.3$ vs. $2.0 \pm 0.2, p=0.0001)$. They also presented a higher rate of severe dyspnoea $(\geq 5)$ at discharge (23 [34.3\%] vs. 36 [19.1\%], $p=0.02$ ). Opioids were used in 41 (15.9\%), mean dose $8.7 \pm 0.8 \mathrm{mg}$ Morphine Equivalent Daily Dose. HF patients had worse EuroQoL $5 \mathrm{~d}$ scores than those with RD, due to mobility problems (118 [62.1\%] vs. 28 [41.8\%], $p=0.004)$, and lower punctuation in Visual Analogue Scale (57.9 \pm 1.6 vs. $65.6 \pm 1.0, p=0.006)$.

Conclusions: About a quarter of patients admitted with HF or RD persist with severe dyspnoea at discharge. Opioids are probably underused. HF patients have less dyspnoea than patients with RD but present worse quality of life.
\end{abstract}

Keywords: Dyspnoea, Heart failure, Chronic obstructive pulmonary disease, Morphine, EuroQoL 5d

\section{Background}

Dyspnoea is one of the most disabling symptoms of heart failure (HF) and respiratory diseases (RD), [1] and the main reason that leads to hospital admission [2]. This symptom surpasses the physical dimension and has a major social and emotional impact [3]. Despite its importance and the well-validated scales available, dyspnoea is not routinely assessed $[4,5]$. The way to express breathlessness by patients is variable, and it can be difficult

\footnotetext{
* Correspondence: mmselles@secardiologia.es

${ }^{1}$ Department of Cardiology, Hospital General Universitario Gregorio Marañón, Doctor Esquerdo 46, 28007 Madrid, Spain

${ }^{3}$ Universidad Complutense, Madrid, Spain

Full list of author information is available at the end of the article
}

to assess objectively the intensity of dyspnoea [6]. In addition, many patients tend to self-limit the intensity of their physical activity and might not feel incapacitating dyspnoea despite being in poor functional class [7]. An effort to quantify the severity of breathlessness is justified, since it is a factor of poor prognosis and is associated with worse outcomes, higher mortality rates, and longer hospital stay [8]. Due to these reasons dyspnoea has been recently recommended as a main endpoint of clinical trials [4]. However, there are few studies that specifically assess the severity of breathlessness, especially in the cardiovascular field $[4,5]$. Most of the studies of dyspnoea that have been carried out in $\mathrm{HF}$ 
have been derived from post hoc analysis of large randomized trials [2, 9]. There are few studies designed specifically to measure the intensity and impact of breathlessness on quality of life and the potential improvement that can be achieved after hospital admission [10]. Some patients remain symptomatic at hospital discharge, and would be eligible to receive additional treatment over standard therapies. Some patient's and treatment characteristics may be associated with a higher probability of presenting severe dyspnea. The identification of these characteristics could be useful to prescribe medications with proven benefit, such as opioids.

The main aim of this study is to evaluate the intensity of dyspnoea in patients hospitalised for HF and RD (chronic obstructive pulmonary disease [COPD] and pulmonary fibrosis) at admission and discharge, and its relation with quality of life. We also describe dyspnoea management (especially taking into account the use of opioids) and compare its intensity and evolution in the two groups. Additionally, we aim to ascertain the factors associated with the persistence of a severe intensity of dyspnea at hospital discharge.

\section{Methods}

We performed a descriptive study of dyspnoea performed in Cardiology and Respiratory Medicine Departments using a cross-sectional design in order to assess the magnitude of the problem of dyspnea.

"Hospital without dyspnoea" is a multidisciplinary initiative started in 2014 that aims to reduce the prevalence of dyspnoea in hospitalised patients in our centre with a multidisciplinary approach that includes the departments of Palliative Care, Cardiology, and Respiratory Medicine [11]. We have designed a multiphase quasi-experimental study with a teaching intervention addressed to healthcare professionals. The first phase of this protocol is the present one.

\section{Study population, endpoints and data collection}

We prospectively included all adult patients admitted for $\mathrm{HF}$, and RD exacerbations in our centre from April to September 2016. Exclusion criteria were inhospital death, severe cognitive impairment and not providing consent to participate in the study. All patients were being optimally treated according to standard disease management guidelines. We collected demographic variables, previous medical history (HF, valvular heart disease, ischemic heart disease, respiratory diseases, peripheral arteriopathy, stroke with sequels, presence of cognitive impairment and previous hospital admissions), variables related with treatment before admission (oxygen and continuous positive airway pressure use) and hospitalization variables such as the cause of exacerbation, intensive care unit admission, invasive or non-invasive mechanical ventilation, and diuretics, opioid, benzodiazepines or antidepressant drugs administration.

Medical history data were extracted from previous medical records. Heart failure was defined according to guidelines recommendations [12]. Patients were classified in two groups "preserved and reduced ejection fraction", with a cut-off point of $45 \%$. All patients with heart failure and preserved ejection fraction had diastolic dysfunction defined as the presence of a dilated left atrium (left atrium volume index $>34 \mathrm{~mL} / \mathrm{m} 2$ ), increased left ventricular mass or functional abnormalities, such as an impaired relaxation pattern in echocardiography [12]. COPD was defined as the presence of a post-bronchodilator forced expiratory volume/forced vital capacity relationship less than 0.70 . Severity was graded according to post-bronchodilator predicted forced expiratory volume in three groups (mild $\geq 80 \%$, moderate $50-80 \%$ and severe/very severe $<50 \%$ ) [13]. Pulmonary fibrosis $[14,15]$ was diagnosed if a reticular pattern was present in imaging tests and gas exchange at rest and during exercise was reduced (predicted single-breath carbon monoxide transference $\leq 60 \%$ and desaturation during 6 minutes walk test).

All patients who were admitted for respiratory disease or heart failure were invited to participate in the registry.

Informed consent was obtained from each patient and the study protocol conforms to the ethical guidelines of the 1975 Declaration of Helsinki as reflected in a priori approval by the institution's human research committee.

\section{Dyspnoea measurement}

In order to quantify the intensity of dyspnoea, patients were asked to answer some questions from a questionnaire. Five physicians (JCL, RL, IM, AP, AO) recruited the patients and administered the questionnaires the day of hospital discharge. Patients were asked to select from a 0-10 numerical rating scale [16] the grade of dyspnea they felt at the moment of admission, the worse breathlessness during hospitalization, and at discharge. Severe dyspnoea at discharge was defined as the persistence of a dyspnoea intensity $\geq 5$ points.

\section{Additional assessments}

The assessment also included New York Heart Association functional class, pain evaluation on a 0 to 10 scale (disabling degree was considered to be present if $\geq 5$ ), methods used to relieve breathlessness and communication with primary care doctor about dyspnoea before admission.

\section{Quality of life measurement}

We used the EuroQoL 5d [17] quality of life classification. The questionnaire is detailed in Additional file 1: Appendix 1. 
The EuroQuol 5d is an instrument for measuring the quality of life related to health. The patient values his health in severity levels in five dimensions (mobility, personal care, daily activities, pain, anxiety) and also on a visual analog scale. Each of the 5 dimensions has 3 levels of potential severity: no problems, some problems or moderate problems and severe problems. The analog scale assessment consists of a millimetre line from 0 (worst imaginable health state) to 100 (best imaginable health state). A third element is the global index values obtained for each health status generated by the instrument, which can range from the value 1 (the better health posible) and 0 (death). There are also negative values that are rated as worse than death [18-20].

Depression was valued according to the degree of limitation noted by patients in the "anxiety/depression" dimension of EuroQoL 5d. In this questionnaire, the emotional state is measured in three levels of severity, from 1 ("no problems") to 3 ("extreme problems"). Patients with 2 or 3 points in this dimension have a substantial mood disorder.

\section{Utilization of opioids}

Morphine was considered as the opioid of reference and is the only opioid currently indicated for dyspnoea relief. Other derivatives can be considered as an alternative to patients intolerant to morphine $[21,22]$. We also recorded the number of patients receiving other opioid derives for chronic pain relief. In all cases opioids were used specifically to relieve dyspnoea. In order to quantify the effect of the administered dose in patients receiving treatment with other opioids and assuming the oral route of opioid administration as a point of reference for comparisons, the Morphine Equivalent Daily Dose (MEDD) was calculated. This equivalence was extracted from dose tables that specify dosage equianalgesic efficacy [23].

\section{Statistical analysis}

Continuous variables are presented as mean with standard deviation, 95\% confidence intervals or median with interquartile range. Categorical data are showed as frequencies and percentages. Comparisons of continuous variables were made using the $t$ test for normally distribution data or Wilcoxon rank sum in nonparametric data. Binary variables were contrasted using the $x^{2}$ test and Fisher's exact test. These statistical tests were used to make group comparisons in Tables 1, 2, 3, 4 and 5. Independent predictors of mortality were determined using a logistic regression model. The modelling process involved forward and backward stepwise methods with a threshold for exit set at $P$ higher than 0.10 and for enter at $P$ lower than 0.10. All statistical analysis were two-tailed.
Statistical analysis was performed with the statistical software of STATA (14.0 version).

\section{Results}

During the study period, 268 patients were screened to participate. Finally 258 patients (157 men, 60.6\%) were included as six patients were excluded due to moderate or severe cognitive impairment and four refused to enter the registry. The number of unanswered questions was very low: only eight patients had significant difficulties to answer the survey questions, and all of them left blank the Numerical Rating Scale. A total of 190 (73.6\%) were admitted in the Cardiology Department due to HF decompensation and 68 (26.4\%) in the Respiratory Medicine Department due to RD (62 COPD and six pulmonary fibrosis). Mean age was $74.0 \pm 1.2$ years, and 36 (14.0\%) were octogenarians. Baseline characteristics, medical history, and length of stay are shown in Table 1. Left ventricular dysfunction, ischemic or valvular heart disease, rhythm disturbances, right ventricular dysfunction, and pulmonary hypertension were more usual in patients suffering from HF, than in those with RD. The opposite happened with obstructive sleep apnoea and domiciliary oxygen therapy. We found a trend towards longer length of stay in patients who presented with severe dyspnoea at admission $(11.4 \pm 1.8$ vs. $8.4 \pm 0.5$ days in those without severe dyspnoea at admission, $p=0.06$ ).

\section{Dyspnoea management}

Treatments administered during admission are detailed in Table 2. Patients suffering from HF were more often admitted to intensive care units and received diuretics and benzodiazepines more frequently than patients with RD. Eight patients received tramadol (3.1\%) and one patient was treated with codeine $(0.4 \%)$.

In patients treated with opioids, 15 (36.6\%) received continuous treatment and 26 (63.4\%) only intermittent administration for dyspnoea crisis management. The mean opioid dose was $8.7 \pm 0.8 \mathrm{mg}$ MEDD, with higher doses in patients with RD $(12.4 \pm 3.3 \mathrm{mg} v s .8 .0 \pm 0.6 \mathrm{mg}$ in HF, $p=0.03)$. Patients admitted to Critical Care Units were more commonly treated with opioids (17 [23.9\%] vs. $24[12.8 \%]$ in those admitted directly to general wards, $p=0.04$ ). Opioid prescription was also more frequent in patients that persisted with severe dyspnoea at discharge (16 [27.1\%] vs. 25 [12.7\%] in patients with milder dyspnoea at discharge, $p=0.01)$, as was continuous opioid administration during admission (9 [56.3\%] vs. 6 [24.0], respectively, $p=0.04)$. The dosage of opioids was higher in patients with a continuous treatment $(11.3 \pm 1.8 \mathrm{mg} v s .7 .2 \pm 0.5 \mathrm{mg}$ in those without, $p=0.01)$, but the amount of drug administered was not related to the degree of dyspnoea at discharge (severe dyspnoea $9.6 \pm 1.7 \mathrm{mg}$ vs. $8.3 \pm 0.7 \mathrm{mg}$ in milder dyspnoea, $p=0.41$ ). 
Table 1 Baseline characteristics and comorbidities

\begin{tabular}{|c|c|c|c|c|}
\hline & $\begin{array}{l}\text { Total } \\
N=258\end{array}$ & $\begin{array}{l}\text { Heart Failure } \\
N=190\end{array}$ & $\begin{array}{l}\text { Respiratory Disease } \\
N=68\end{array}$ & $p$ \\
\hline Age, years & $74.0 \pm 1.2$ & $73.5 \pm 1.4$ & $75.1 \pm 1.9$ & 0.53 \\
\hline Male Sex & $157(60.9)$ & $104(54.7)$ & $53(78.0)$ & 0.0001 \\
\hline Previous history of heart disease & $170(65.9)$ & $149(78.4)$ & $21(30.8)$ & 0.0001 \\
\hline Sinus Rhythm & $138(53.5)$ & $78(41.1)$ & $60(88.2)$ & 0.001 \\
\hline Ischemic Heart Disease & $106(41.1)$ & $91(47.9)$ & $15(22.1)$ & 0.001 \\
\hline Valvular Heart Disease & $87(33.7)$ & $73(38.4)$ & $14(20.6)$ & 0.02 \\
\hline Left ventricular ejection fraction $<45 \%$ & $102(39.5)$ & $99(52.1)$ & $3(4.4)$ & 0.0001 \\
\hline Unknown left ventricular ejection fraction & $18(7.0)$ & 0 & $18(26.4)$ & 0.0001 \\
\hline Known Right ventricle dysfunction & $62(24.0)$ & $59(31.1)$ & $3(4.4)$ & 0.001 \\
\hline Known Pulmonary Hypertension & $104(40.3)$ & $82(43.2)$ & $12(17.6)$ & 0.001 \\
\hline Obstructive Sleep Apnea Syndrome & $30(11.6)$ & $17(8.9)$ & $13(19.1)$ & 0.03 \\
\hline Peripheral Arterial Disease & $31(12.0)$ & $24(12.6)$ & $7(10.3)$ & 0.67 \\
\hline Stroke & $16(6.2)$ & $15(7.9)$ & $1(1.5 \%)$ & 0.03 \\
\hline Cognitive impairment & $8(3.1)$ & $5(2.6)$ & $3(4.4 \%)$ & 0.48 \\
\hline Previous hospital admissions & & & & 0.0001 \\
\hline Heart Failure & $102(39.5)$ & $101(53.2)$ & $1(1.5)$ & \\
\hline COPD or Pulmonary Fibrosis & $49(19.0)$ & $1(0.5)$ & $48(70.6)$ & \\
\hline Domiciliary oxygen & $32(12.4)$ & $5(2.6)$ & $27(39.7)$ & 0.0001 \\
\hline Continuous Positive Airway Pressure at home & $24(9.3)$ & $13(6.8)$ & $11(16.2)$ & 0.03 \\
\hline Length of stay & $8.7 \pm 0.5$ & $9.3 \pm 0.6$ & $7.3 \pm 0.4$ & 0.06 \\
\hline Living alone & $64(24.8)$ & $46(24.2)$ & $18(26.5)$ & 0.87 \\
\hline Lives with family & $190(73.6)$ & $142(74.7)$ & $48(70.6)$ & \\
\hline Living in residency & $3(1.2)$ & $2(1.1)$ & $1(1.5)$ & \\
\hline
\end{tabular}

Data are shown as number of patients and percentages (mean \pm standard deviation for age). Categorical variables are contrasted using the $x^{2}$ test and Fisher's exact test and comparison for age is made using the $t$ test

At hospital discharge, only 16 patients with severe dyspnoea (27.1\%) received specific treatment with opioids for dyspnoea relief.

Table 2 shows the methods used for dyspnoea relief prior to hospitalization, and former communication with the primary care physician regarding breathlessness. Patients admitted for RD had previously consulted with their general practitioner for this reason more frequently than those with HF. The most frequent method used for the relief of dyspnoea in HF patients was sleeping with more than one pillow or the head of the bed elevated. On the other hand, continuous positive airway pressure, inhalers, and supplemental oxygen were more common in $\mathrm{RD}$ patients.

\section{Degree of perceived dyspnoea and quality of life impairment}

Dyspnoea severity during hospital admission is shown in Fig. 1. Patients with RD reported higher intensity of breathlessness than those with HF. The degree of dyspnoea improved during hospitalization with a similar reduction in both groups $(5.2 \pm 0.2$ points in HF vs.
$4.9 \pm 0.3$ points in RD, $p=0.41)$. Fifty-nine patients $(23.1 \%)$ still presented severe dyspnoea ( $>5$ points) at discharge (36 [19.1\%] in HF vs. 23 [34.3\%] in RD, $p=0.02$ ). Patients admitted to intensive care units presented lower level of dyspnoea at discharge $(1.9 \pm 0.3$ vs. $2.5 \pm 0.2$ points in those admitted directly to the general ward, $p=0.02$ ), although they presented a similar degree of dyspnoea at admission ( $7.5 \pm 0.2$ vs. $7.5 \pm 0.3$ points, respectively, $p=$ $0.98)$. The intensity of dyspnoea at hospital discharge was different according to COPD severity $(2.4 \pm 0.1$ points in mild; $2.5 \pm 0.2$ points in moderate; $3.6 \pm 0.2$ points in severe/very severe, $p=0.02$ ). Patients with preserved left ventricular ejection fraction had higher intensity of dyspnoea at discharge $(2.7 \pm 0.2$ points $)$ compared to reduced left ventricular ejection fraction (2.0 \pm 0.3 points), $p=0.03$.

New York Heart Association functional class at hospital discharge was similar in the two groups (I or II: 142 [74.7\%] in HF vs. 48 [71.6\%] in RD, $p=0.62$ ), and $67(26.1 \%)$ remained at discharge in functional class III or IV (48 [ 25.3\%] in HF and 19 [28.4\%] in $\mathrm{RD}, p=0.62)$. 
Table 2 Treatment administered during admission and methods recognized by the patients themselves for dyspnea relief prior to hospitalization

\begin{tabular}{|c|c|c|c|c|}
\hline & $\begin{array}{l}\text { Total } \\
N=258\end{array}$ & $\begin{array}{l}\text { Heart Failure } \\
N=190\end{array}$ & $\begin{array}{l}\text { Respiratory Disease } \\
N=68\end{array}$ & $p$ \\
\hline \multicolumn{5}{|l|}{ Location and treatment administered during admission } \\
\hline Intensive care unit admission & $71(27.5)$ & $62(32.6)$ & $9(13.2)$ & 0.002 \\
\hline Non-invasive mechanical ventilation & $48(18.6)$ & $31(16.3)$ & $17(25.0)$ & 0.11 \\
\hline Diuretics & $216(83.7)$ & $187(98.4)$ & $29(42.6)$ & 0.0001 \\
\hline Bronchodilators & $85(33.0)$ & $32(16.8)$ & $53(77.9)$ & 0.0001 \\
\hline Benzodiazepines & $138(53.4)$ & $112(58.9)$ & $26(38.2)$ & 0.004 \\
\hline Opioids & $41(15.9)$ & $34(17.9)$ & $7(10.3)$ & 0.17 \\
\hline MEDD (mg) & $8.7 \pm 0.8$ & $8.0 \pm 0.6$ & $12.4 \pm 3.3$ & 0.03 \\
\hline Antidepressants & $34(13.2)$ & $24(12.6)$ & $10(14.9)$ & 0.67 \\
\hline \multicolumn{5}{|l|}{ Methods used for dyspnoea relief prior to hospitalization } \\
\hline Sleeping with high headboard & $140(54.3)$ & $115(60.5)$ & $25(36.8)$ & 0.001 \\
\hline Fan & $16(6.2)$ & $15(7.9)$ & $1(1.5)$ & 0.03 \\
\hline Oxygen & $46(17.8)$ & $15(7.9)$ & $31(45.6)$ & 0.0001 \\
\hline Continuous Positive Airway Pressure & $24(9.3)$ & $11(5.8)$ & $13(19.1)$ & 0.003 \\
\hline Inhalers & $91(35.3)$ & $37(19.5)$ & $54(79.4)$ & 0.0001 \\
\hline None & $58(22.5)$ & $51(26.8)$ & $7(10.3)$ & 0.003 \\
\hline Communication with GP regarding dyspnoea & $153(59.3)$ & $98(51.6)$ & $54(79.4)$ & 0.0001 \\
\hline Seeking for medical attention during admission due to acute dyspnoea & $96(37.2)$ & $73(38.4)$ & $23(33.8)$ & 0.53 \\
\hline Thinks that treatment received could be better & $91(35.3)$ & $65(34.2)$ & $26(38.2)$ & 0.57 \\
\hline
\end{tabular}

GP General practitioner, MEDD, Morphine Equivalent Daily Dosage

Data are shown as number of patients and (mean \pm standard deviation for Mean Morphine Equivalent Daily Dosage [MEDD]). Categorical variables are contrasted using the $x^{2}$ test and Fisher's exact test and comparison for MEDD is made using the $t$ test

Table 3 Univariate analysis of severe dyspnoea-related factors at hospital discharge

\begin{tabular}{llll}
\hline & Dyspnoea $<5$ points & Dyspnoea $\geq 5$ points & N=59 \\
& $N=199$ & $18(30.5)$ & 0.221 \\
Age $>70$ years & $44(22.1)$ & $15(25.4)$ & 0.009 \\
Female Sex & $86(43.2)$ & $23(39.0)$ & 0.017 \\
Respiratory Disease & $44(22.1)$ & $40(67.8)$ & 0.876 \\
History of heart disease & $129(64.8)$ & $34(57.6)$ & 0.552 \\
Sinus rhythm & $103(51.8)$ & $17(28.8)$ & 0.08 \\
Preserved ejection fraction & $86(43.2)$ & $16(27.1)$ & 0.016 \\
Severe COPD & $26(13.1)$ & $47(79.7)$ & $<0.0001$ \\
Previous admission for exacerbation & $103(51.8)$ & $16(27.1)$ & 0.001 \\
Domiciliary oxygen therapy & $17(8.5)$ & $14(23.7)$ & 0.21 \\
Admission in the intensive care unit & $56(28.1)$ & $14(23.7)$ & 0.38 \\
Non-invasive mechanical ventilation & $33(16.6)$ & $20(33.9)$ & 0.003 \\
Opioid treatment & $32(16.1)$ & $47(79.7)$ & $<0.0001$ \\
Mobility problems & $100(50.3)$ & $41(70.5)$ & $<0.0001$ \\
Depression & $73(36.7)$ & & \\
\hline
\end{tabular}


Table 4 Independent predictors of severe dyspnoea ( $\geq 5$ points) at hospital discharge by logistic regression model

\begin{tabular}{lll}
\hline Variable & OR $(95 \% \mathrm{Cl})$ & $P$ \\
\hline Age & $1.1(1.02-1-2)$ & 0.004 \\
Female Sex & $2.2(1.2-2.3)$ & 0.005 \\
Depression & $3.9(2.1-7.2)$ & 0.001 \\
Non admitted in an intensive care unit & $3(1.1-8.3)$ & 0.05 \\
Respiratory Disease & $1.2(1.1-1.4)$ & 0.001 \\
\hline
\end{tabular}

$N=258 ; C l$ Confidence Interval, OR Odds Ratio

Dyspnoea at discharge was higher in patients with depression than in those without $(3.3 \pm 0.3$ vs. $1.6 \pm 0.2$ points, $p<0.0001)$, with no relevant differences regarding dyspnoea intensity at admission $(7.7 \pm 0.2$ vs. $7.3 \pm 0.2$ points, respectively, $p=0.12$ ), nor in the highest intensity during hospitalization $(5.9 \pm 0.3$ vs. $5.6 \pm 0.2$ points, respectively, $p=0.33$ ).

The independent predictors for severe dyspnoea at discharge by logistic regression modelling were age, female sex, depression, not admitted in an intensive care unit, and respiratory disease (Tables 3 and 4).

Age was also a predictor of higher degree of dyspnoea (as a continuous variable) at hospital discharge. Regarding the magnitude of dyspnoea decrease during hospital admission and its relation with treatment administered, the unique independent predictor of a larger decrease in dyspnoea during the course of hospitalisation was opioid treatment $(p=0.028)$.

Data regarding the score of pain are also shown in Fig. 1. Patients with HF reported higher pain scores than those with $\mathrm{RD}$, although the differences were not significant at discharge. A total of 31 patients (12.2\%) presented with disabling pain at discharge. Scores on the different dimensions of EuroQoL 5d are described in Table 5. Compared with patients with $\mathrm{RD}$, those with HF had more mobility problems and had lower scores in Visual Analogic Scale rating quality of life, and lower index values. They also presented more pain and felt more depressed, but these results did not reach statistical significance.

\section{Discussion}

We found that patients admitted for HF and RD had an important reduction in health-related quality of life, in part as a result of dyspnoea. Dyspnoea is severe in the majority of patients at admission and improves during hospitalization, but remains intense at hospital discharge in about a quarter of patients. Opioids were seldom prescribed. Interestingly, HF patients had less dyspnoea than patients with RD but, despite that, they presented worse quality of life.

The higher burden of dyspnoea among patients admitted for RD could be expected, as HF patients present this symptom mainly in relation with pulmonary congestion. In fact, in those suffering from right-sided HF, dyspnoea is less notable and peripheral congestion prevails. Few studies have assessed the progress of dyspnoea during hospital admission. Dinino et al. [24] showed that dyspnoea severity improved rapidly during hospitalization. These authors found higher dyspnoea at baseline and admission and slower resolution of dyspnoea symptoms in patients with RD with respect to HF. Our results are consistent with this previous experience.

We also found that female sex was an independent predictor of severe dyspnoea at discharge. Previous studies have shown that women are a particularly vulnerable group $[25,26]$, with an increased risk of depressive symptoms added to breathlessness [1]. In fact, although many patients were anxious or depressed, treatment with antidepressants was administered to a low proportion of patients (13.2\%). Depression was probably underdiagnosed too, as it can be masked by other symptoms common in HF and RD [27, 28], and diagnosis was performed using a questionnaire mainly designed to quantify dyspnoea. The benefits derived from depression treatment are substantial, as it improves morbidity and mortality [29] and antidepressants are safe in patients with HF and RD [30]. It is difficult to establish if dyspnoea caused depression or if low mood was responsible, in part, for the sensation of shortness of breath. In any case it seems to be room for improvement in its management.

Table 5 Patients presenting limitations in EuroQoL 5d

\begin{tabular}{lllll}
\hline & Total & Heart Failure & Respiratory Disease \\
$N=258$ & 190 & $28(41.2)$ & $p$ \\
Mobility & $146(56.6)$ & $118(62.1)$ & $23(33.8)$ & 0.004 \\
Self-care & $96(37.2)$ & $73(38.4)$ & $41(60.3)$ & 0.55 \\
Usual activities & $160(62.0)$ & $119(62.6)$ & $23(33.8)$ & 0.88 \\
Pain/discomfort & $105(40.7)$ & $82(43.2)$ & $28(41.2)$ & 0.25 \\
Anxiety/depression & $114(44.2)$ & $86(45.3)$ & $65.6 \pm 1.0$ & 0.62 \\
Visual analogic scale & $59.9 \pm 1.3$ & $57.9 \pm 1.6$ & $0.73 \pm 0.04$ & 0.006 \\
EuroQoL Index & $0.63 \pm 0.02$ & $0.60 \pm 0.03$ & 0.01 \\
\hline
\end{tabular}

Data are shown as number of patients and mean \pm standard deviation for Visual analogic scale and EuroQoL Index. Categorical variables are contrasted using the $\mathrm{X}^{2}$ test and Fisher's exact test. Comparisons for Visual analogic scale and EuroQoL Index are made using the $t$ test 


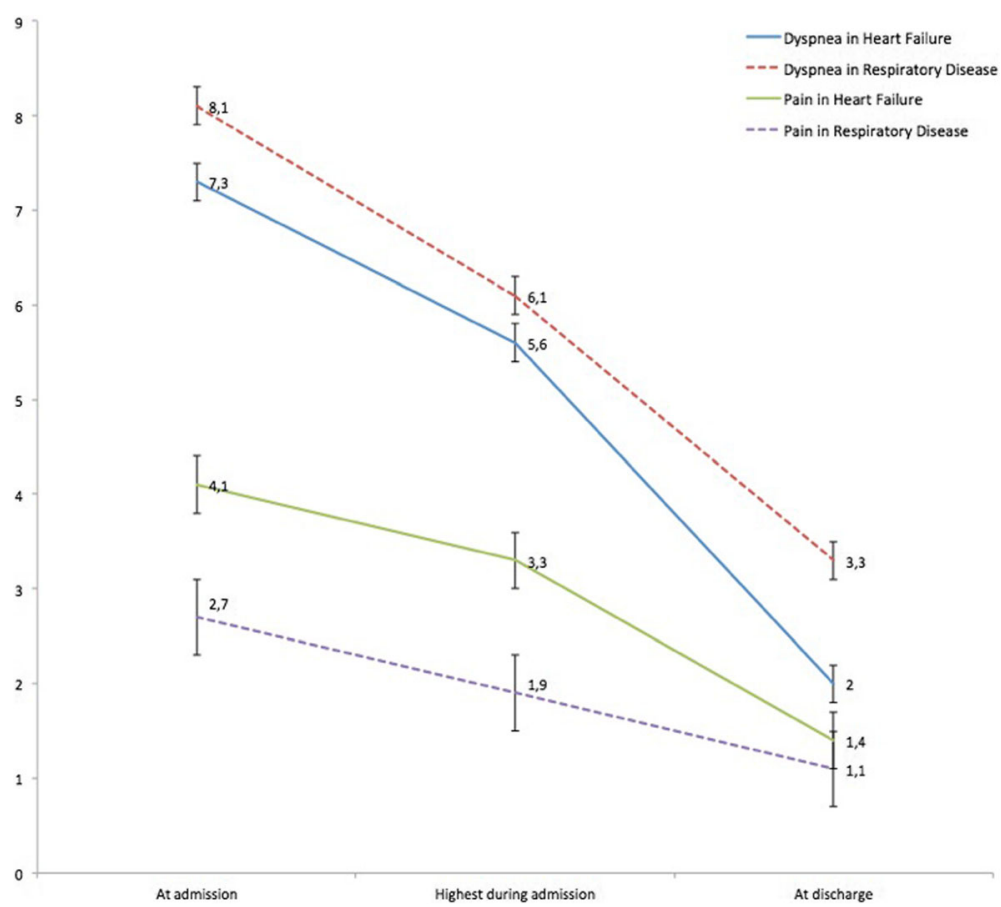

Fig. 1 Progression of dyspnoea and pain during hospital admission. The figure shows the evolution of dyspnoea and pain during admission in patients with heart failure (continuous line) and respiratory diseases (dashed line). The data represent the mean value according to the Numerical Rating Scale in three moments: at admission, the maximum value perceived during admission and hospital discharge. Error bars represent the standard deviation. "Highest during admission" refers to the highest value of dyspnoea or pain perceived during the course of hospitalization after excluding the symptoms at the time of admission

Despite the frequency of severe dyspnoea and the fact that there are effective tools for treatment, such as opioids [31, 32], an extended therapeutic nihilism in patients with persistent dyspnoea has been described [33]. In our study only $27 \%$ of patients with severe dyspnoea at discharge received a medical action addressed to improve it. This is a two-way phenomenon, as $23 \%$ used no method for dyspnoea relief before admission and $41 \%$ had no previous communication with their general practitioner regarding dyspnoea.

There is a widespread non-familiarity with the use of scores to quantify the intensity of dyspnoea [34]. Our data emphasize the importance of quantifying dyspnoea and to have a proactive attitude in its management. In this regard, the first step should be to improve the professional skills to recognize, quantify, and treat dyspnoea. A previous experience in primary care with COPD has shown positive outcomes [35]. Even a small difference in the degree of dyspnoea is important and 1 point of perceived improvement in the numerical scale can be a great relief for the patient [6]. In spite of this data, we found that opioid use was unusual and only $5 \%$ received continuous treatment.

Interestingly, admission to an intensive care unit was a protective factor for dyspnoea at discharge, even though dyspnoea at admission was similar to patients admitted directly to the general ward. The justification of this effect is not clear, but is probably related with the twicehigher rate of opioids prescription in intensive care with respect to general ward.

Although patients suffering from HF had less dyspnoea at discharge than those with RD, they had a worse quality of life, mainly due to mobility limitations. Mobility problems are more common in HF and have a multifactorial origin, including skeletal muscle anomalies due to reduced blood supply, also called HF-related myopathy [36]. Pain was also more frequent in HF patients compared to the ones with RD. This could be, in part, explained by the occurrence of angina, as almost half of our HF patients had ischemic heart disease.

Our study supports the need for improvement in the caregiving to patients with HF and RD, in whom dyspnoea is a disabling symptom that worsens quality of life and surpasses the importance of other symptoms, like pain.

\section{Limitations}

This is a cross-sectional study in a hospital setting, with no after-discharge follow-up. Also, due to its monocentric nature, its generalizability may be limited and our data might not represent daily practice and reality of other hospitals. In order to facilitate information collection and minimize data loss we administered a single 
survey on the day of discharge, so patients may have overstated or minimized the intensity of dyspnoea at hospital admission. This design had a more focused approach with daily practice. We included all patients admitted with HF, so the prevalence of dyspnoea may have been underestimated, due to the presence of strictly right-sided HF in some patients. Finally, most of our patients presented HF so there may have been a lack of statistical power to find significant differences between those patients and the low number of patients $\mathrm{RD}$ in some variables.

\section{Conclusions}

About a quarter of patients admitted with HF or RD persist with severe dyspnoea at discharge. Opioids are probably underused. HF patients have less dyspnoea than patients with RD but, despite this fact, present worse quality of life.

\section{Additional file}

Additional file 1: Appendix 1: Survey administered the day of hospital discharge to patients admitted for heart failure, COPD or pulmonary fibrosis. Patient's questionnaire administered the day of hospital discharge to quantify quality of life, dyspnea assessment and relief methods. (DOCX 106 kb)

\section{Abbreviations}

COPD: Chronic obstructive pulmonary disease; HF: Heart failure; MEDD: Morphine equivalent daily dose; NRS: Numerical rating scale; RD: Respiratory disease

\section{Acknowledgements}

Other investigators from the Hospital Without Dyspnoea initiative: Ingrid Frías, José Rafael Terán.

\section{Funding}

This study was supported in part by the grant FIS PI 012_2734 Instituto de Salud Carlos III, co-financed by the European Union through the Fondo Europeo de Desarrollo Regional (FEDER, "Una manera de hacer Europa").

\section{Availability of data and materials}

The datasets used and/or analysed during the current study are available from the corresponding author on reasonable request.

\begin{abstract}
Authors' contributions
LV, JMNO, LPM, MMS, AO, RL, JCL, FFA, IM, AP made substantial contributions to conception and design, or acquisition of data, or analysis and interpretation of data; LV, JMNO, LPM, MMS, AO, RL, JCL, FFA, IM, AP have been involved in drafting the manuscript or revising it critically for important intellectual content; $L V$, JMNO, LPM, MMS, AO, RL, JCL, FFA, IM, AP given final approval of the version to be published. Each author should have participated sufficiently in the work to take public responsibility for appropriate portions of the content; and LV, JMNO, LPM, MMS, AO, RL, JCL, FFA, IM, AP agreed to be accountable for all aspects of the work in ensuring that questions related to the accuracy or integrity of any part of the work are appropriately investigated and resolved. All authors read and approved the final manuscript.
\end{abstract}

\section{Competing interests}

The authors declare that they have no competing interests.

\section{Consent for publication}

Non applicable.

\section{Ethics approval and consent to participate}

The study received approval by the institution's human research committee (Gregorio Marañon Institutional Review Board and Ethics Committee). Informed consent was obtained from each patient and the study protocol conforms to the ethical guidelines of the 1975 Declaration of Helsinki.

\section{Publisher's Note}

Springer Nature remains neutral with regard to jurisdictional claims in published maps and institutional affiliations.

\section{Author details}

'Department of Cardiology, Hospital General Universitario Gregorio Marañón, Doctor Esquerdo 46, 28007 Madrid, Spain. ${ }^{2}$ Department of Palliative Care, Hospital General Universitario Gregorio Marañón, Madrid, Spain. ${ }^{3}$ Universidad Complutense, Madrid, Spain. ${ }^{4}$ Department of Respiratory Medicine, University Hospital Gregorio Marañón, Madrid, Spain. ${ }^{5}$ Universidad Europea, Madrid, Spain

Received: 7 March 2017 Accepted: 14 May 2017

Published online: 22 May 2017

\section{References}

1. Hayen A, Herigstad M, Pattinson KTS. Understanding dyspnea as a complex individual experience. Maturitas. 2013;76:45-50.

2. Metra M, Teerlink JR, Felker GM, Greenberg BH, Filippatos G, Ponikowski P, Teichman SL, Unemori E, Voors AA, Weatherley BD, et al. Dyspnoea and worsening heart failure in patients with acute heart failure: results from the Pre-RELAX-AHF study. Eur J Heart Fail. 2010;12:1130-9.

3. Parshall MB, Schwartzstein RM, Adams L, Banzett RB, Manning HL, Bourbeau J, Calverley PM, Gift AG, Harver A, Lareau SC, et al. An Official American Thoracic Society Statement: Update on the Mechanisms, Assessment, and Management of Dyspnea. Am J Respir Crit Care Med. 2012;185:435-52.

4. Johnson MJ, Cleland JG, Clark AL. Measurement of breathlessness in clinical trials in patients with chronic heart failure: the need for a standardized approach: a systematic review. Eur J Heart Fail. 2010;12:137-47.

5. Johnson MJ. The management of dyspnoea in chronic heart failure. Curr Opin Support Palliat Care. 2010;4:63-8.

6. Oxberry SG, Bland JM, Clark AL, Cleland JGF, Johnson MJ. Minimally clinically important difference in chronic breathlessness: Every little helps. Am Heart J. 2012;164:229-35.

7. Sassi-Dambron DE, Eakin EG, Ries AL, Kaplan RM. Treatment of Dyspnea in COPD: A Controlled Clinical Trial of Dyspnea Management Strategies. Chest. 1995;107:724-9.

8. Stevens JP, Baker K, Howell MD, Banzett RB. Prevalence and Predictive Value of Dyspnea Ratings in Hospitalized Patients: Pilot Studies. PLoS ONE. 2016;11:e0152601

9. Metra M, Weatherley BD, Dittrich HC, Givertz MM, Massie BM, O'Connor CM, Ponikowski P, Teerlink JR, Voors AA, Cotter G. Dyspnoea in patients with acute heart failure: an analysis of its clinical course, determinants, and relationship to 60-day outcomes in the PROTECT pilot study. Eur J Heart Fail. 2010;12:499-507.

10. Higginson IJ, Bausewein C, Reilly CC, Gao W, Gysels M, Dzingina M, McCrone P, Booth S, Jolley CJ, Moxham J. An integrated palliative and respiratory care service for patients with advanced disease and refractory breathlessness: a randomised controlled trial. Lancet Respir Med. 2014;2:979-87.

11. Vicent L, Puente-Maestu L, Artajona E, Fernández-Avilés F, Martínez-Sellés M. Hospital without dyspnea: rationale and design of a multidisciplinary intervention. J Geriatr Cardiol. 2016;13:625-31.

12. Ponikowski P, Anker SD, Bueno H, Cleland JG, Coats AJ, Falk V, GonzálezJuanatey JR, Harjola VP, Jankowska EA, Jessup M, Linde C, Nihoyannopoulos P, Parissis JT, Pieske B, Riley JP, Rosano GM, Ruilope LM, Ruschitzka F, Rutten FH, van der Meer P; Authors/Task Force Members; Document Reviewers.: 2016 ESC Guidelines for the diagnosis and treatment of acute and chronic heart failure: The Task Force for the diagnosis and treatment of acute and chronic heart failure of the European Society of Cardiology (ESC). Developed with the special contribution of the Heart Failure Association (HFA) of the ESC. Eur J Heart Fail 2016, 18:891-975.

13. Vestbo J, Hurd SS, Agustí AG, Jones PW, Vogelmeier C, Anzueto A, Barnes PJ, Fabbri LM, Martinez FJ, Nishimura M, et al. Global Strategy for the Diagnosis, Management, and Prevention of Chronic Obstructive Pulmonary Disease. Am J Respir Crit Care Med. 2013;187:347-65. 
14. Raghu G, Zhang Y, Garcia CA, Azuma A, Behr J, Brozek JL, Collard HR, Cunningham W, Homma S, Johkoh T, Martinez FJ, Myers J, Protzko SL, Richeldi L, Rind D, Selman M, Theodore A, Wells AU, Hoogsteden H, Schünemann HJ; American Thoracic Society; European Respiratory society; Japanese Respiratory Society; Latin American Thoracic Association.: An Official ATS/ERS/JRS/ALAT Clinical Practice Guideline: Treatment of Idiopathic Pulmonary Fibrosis. An Update of the 2011 Clinical Practice Guideline. Am J Respir Crit Care Med 2015, 192:e3-19.

15. American Thoracic Society. Idiopathic pulmonary fibrosis: diagnosis and treatment. International consensus statement. American Thoracic Society (ATS), and the European Respiratory Society (ERS). Am J Respir Crit Care Med. 2000;161:646-664.

16. Borg GA. Psychophysical bases of perceived exertion. Med Sci Sports Exerc. 1982;14:377-81.

17. Euro QoL 5D. Euro Qol Research Foundation. User quide. Euro QoL 5D. 2016. http://www.euroqol.org/fileadmin/user_upload/Documenten/PDF/ Folders_Flyers/EQ-5D-3L_UserGuide_2015.pdf. Accessed 15 Oct 2016.

18. Balestroni G. Euro Qol-5D (EQ-5D): an instrument for measuring quality of life. Monaldi Arch Chest Dis. 2012;78:155-9.

19. Rabin R1: EQ-5D: a measure of health status from the Euro Qol Group. Ann Med. 2001;33:337-343.

20. Herdman M, Badia X, Berra S. Euro Qol-5D: a simple alternative for measuring health-related quality of life in primary care. Aten Primaria. 2016;48:425-30.

21. Simon ST, Köskeroglu P, Gaertner J, Voltz R: Fentanyl for the Relief of Refractory Breathlessness: A Systematic Review. J Pain Symptom Manage, 46:874-886.

22. Barnes H, Smallwood N, Manser R. Opioids for the palliation of refractory breathlessness in adults with advanced disease and terminal illness. Cochrane Database Syst Rev. 2016;31:CD011008.

23. Pereira J, Lawlor P, Vigano A, Dorgan M, Bruera E. Equianalgesic Dose Ratios for Opioids. J Pain Symptom Manage. 2001;22:672-87.

24. DiNino E, Stefan MS, Priya A, Martin B, Pekow PS, Lindenauer PK: The Trajectory of Dyspnea in Hospitalized Patients. J Pain Symptom Manage. 2016:51:682-689.e681.

25. Watson L, Vestbo J, Postma DS, Decramer M, Rennard S, Kiri VA, Vermeire PA, Soriano JB. Gender differences in the management and experience of Chronic Obstructive Pulmonary Disease. Respir Med. 2004;98:1207-13.

26. Sørheim I-C, Johannessen A, Gulsvik A, Bakke PS, Silverman EK, DeMeo DL. Gender differences in COPD: are women more susceptible to smoking effects than men? Thorax. 2010;65:480-5.

27. Echols MR. Clinical trial evidence for treatment of depression in heart failure. Heart Fail Clin. 2011;7:81-8.

28. Caraceni A, Kaasa S, Bennett MI, Brunelli C, Cherny N, Dale O, De Conno F, Fallon M, Hanna M, Haugen DF, Juhl G, King S, Klepstad P, Laugsand EA, Maltoni M, Mercadante S, Nabal M, Pigni A, Radbruch L, Reid C, Sjogren P, Stone PC, Tassinari D, Zeppetella G; European Palliative Care Research Collaborative (EPCRC); European Association for Palliative Care (EAPC). Use of opioid analgesics in the treatment of cancer pain: evidence-based recommendations from the EAPC. Lancet Oncol 2012, 13:e58-e68.

29. Shapiro PA. Treatment of depression in patients with congestive heart failure. Heart Fail Rev. 2009;14:7-12

30. Parissis J, Paraskevaidis I, Kremastinos DT. Sertraline for the treatment of depression in coronary artery disease and heart failure. Expert Opin Pharmacother. 2007;8:1529-37.

31. Johnson M, McDonagh TA, Harkness A, McKay SE, Dargie HJ. Morphine for the relief of breathlessness in patients with chronic heart failure-a pilot study. Eur J Heart Fail. 2002:4:753-6.

32. Jennings A, Davies A, Higgins J, Gibbs J, Broadley K. A systematic review of the use of opioids in the management of dyspnoea. Thorax. 2002;57:939-44.

33. Currow DC, Abernethy AP, Ko DN. The active identification and management of chronic refractory breathlessness is a human right. Thorax. 2014;69(4):393-4.

34. Baker K, Barsamian J, Leone D, Donovan BC, Williams D, Carnevale K, Lansing R, Banzett R. Routine dyspnea assessment on unit admission. Am J Nurs. 2013;113:42-50.

35. Godycki-Cwirko M, Zakowska I, Kosiek K, Wensing M, Krawczyk J, Kowalczyk A. Evaluation of a tailored implementation strategy to improve the management of patients with chronic obstructive pulmonary disease in primary care: a study protocol of a cluster randomized trial. Trials. 2014;15:1-8.

36. Witte KK, Clark AL. Why does chronic heart failure cause breathlessness and fatigue? Prog Cardiovasc Dis. 2007;49:366-84.

\section{Submit your next manuscript to BioMed Central and we will help you at every step:}

- We accept pre-submission inquiries

- Our selector tool helps you to find the most relevant journal

- We provide round the clock customer support

- Convenient online submission

- Thorough peer review

- Inclusion in PubMed and all major indexing services

- Maximum visibility for your research

Submit your manuscript at www.biomedcentral.com/submit
() BioMed Central 